\title{
Transitions as sites of socialization in family interaction outdoors
}

Tiina Keisanen, University of Oulu

Mirka Rauniomaa, University of Helsinki

Pauliina Siitonen, University of Oulu

\begin{abstract}
In this study, we explore transitions in social interaction as sites for socialization: we discuss the significance of transitions for how participants establish an appropriate orientation to an activity, provide each other opportunities to participate in the activity and make the social order of the activity visible. We draw on ethnomethodological conversation analysis and video recordings in English and Finnish in which families with children engage in the activity of foraging, i.e. picking wild produce. We focus on transitions between what can roughly be described as 'searching' and 'picking', to examine how the timing and length of each are adjusted in relation to local contingencies and how the more experienced participants work in different ways to maintain the less experienced participants' engagement in the foraging. Furthermore, we argue that participants orient to transitions at appropriate points as enabling effective and economical foraging.
\end{abstract}

\section{Introduction}

Everyday life in families consists of different activities, such as mealtimes, household chores, homework, commutes to work and school as well as various hobbies and other leisure-time activities. These social-interactional activities also provide the context for children's socialization and learning, that is, for their becoming competent members and active participants in relevant communities and in society at large (Lave \& Wenger, 1991; Ochs, 1996; see also Keel, 2016). There is currently an 
emerging interest in how transitions between such quotidian activities contribute to practices and opportunities for participation, varying from macro-level perspectives (such as examining how children's identities develop and change in moving from daycare to school; Winther-Lindqvist, 2012) to micro-level studies of social interaction (such as examining how caregivers use directives to initiate a move from an ongoing activity to preparing for bedtime; Goodwin \& Cekaite, 2013). Transitions therefore occupy a good amount of time during the day (Olive, 2004), and learning how to accomplish them is central for the smooth progression of everyday activities.

In this study, we adopt the micro-level approach to explore the situated design and accomplishment of transitions in mundane social interaction between family members. We pay close attention to how participants construct their actions with language and their body and by drawing on the surrounding material resources. We show that transitions are important in establishing an appropriate orientation to an ongoing activity and participation in it, as well as in making the social order of that activity visible. In this way, we argue, transitions provide another example of a site in which participants who are less and more experienced can 'mutually apprentice' one another to meaningful social interaction (Pontecorvo, Fasulo \& Sterponi, 2001). To put it differently, we posit that even though the more experienced participants, typically adults, frequently guide the less experienced participants, typically children, in carrying out an activity, transitions constitute jointly accomplished achievements that are shaped by the participants' moment-to-moment contributions. The focus of our study is on the transitions that occur when families with young children are foraging in the woods, picking wild berries and mushrooms. The cases examined here predominantly concern transitions between what can generally be described as 'searching' and 'picking'. Our main interest is in how the timing and length of each are adjusted in relation to local contingencies and how the adults work in different ways to maintain the children's engagement in the overall foraging activity. 


\section{On socialization, participation and transitions}

For young children, socialization involves their learning to recognize and produce not only linguistic patterns and structures, but also interactional practices and social actions: through instruction and practice, young children acquire the competence to comprehend that their own actions as well as others' have projectable implications and accountable consequences (see, e.g. Forrester, 2013; Keel, 2011; Sidnell, 2010; Wootton, 2007). Furthermore, for children and other less competent members of a community, socialization may entail the adoption of cultural practices that promote the values and norms of the community. For example, Fasulo, Loyd and Padiglione (2007) examine the ways that parents direct children to accomplish household and hygiene activities in Italian and American families, focusing on the implications that the different socialization practices and parenting strategies may have for the children's agency. Fasulo et al. (2007) argue that through practices that range from giving children explicit instructions and assessments to offering them silent assistance and parental control, parents “either emphasize children's agency - thus downplaying the parental role in the accomplishment of actions - or instead emphasize parental involvement in execution and outcome, to the extent of restraining their children's decisional sphere and individual responsibility" (p. 28). Fasulo et al. (2007) demonstrate, for instance, that by giving children options as to how and in which order to carry out various activities (such as taking a shower or taking out the garbage), and by thus breaking up the routine character of the activities, parents foster their children's autonomy and agency (see also Jenkins, 2015). Nevertheless, Fasulo et al. (2007) also point out that by not granting such options and instead exerting parental control, parents highlight the cultural and familial values of certain, possibly domain-specific, everyday activities and promote the expectation that children will also subscribe to them (see also George, 2013). Stated more generally, the adoption of cultural practices and socialization at large can be observed through locally accomplished and managed practices of participation, such as observing how participants display their involvement in an activity (Goodwin \& 
Goodwin, 2004). In this study, we focus on transitions, which we consider as nexuses of action in which the participants are shown to negotiate an appropriate orientation to and participation in an ongoing activity (cf. Goodwin, 2006; Goodwin \& Cekaite, 2013).

Transitions typically encompass changes that participants display in their degree of engagement to one another and their potential joint activity, such changes occurring in openings and closings of entire episodes of face-to-face interaction (e.g. Laurier, 2008; LeBaron \& Jones, 2002; Mondada, 2009; Mortensen \& Hazel, 2014; Robinson, 1998; Tuncer, 2015) as well as in transitions between activities within one episode, or interactive event (e.g. Broth \& Keevallik, 2014; Broth \& Mondada, 2013; Keevallik, 2010; vom Lehn, 2013; Mikkola \& Lehtinen, 2014; Modaff, 2003; Robinson \& Stivers, 2011; Råman, 2017; Veen \& de la Croix, 2016). For example, students have been shown to exploit a variety of means to engage in (Hellermann, 2007; Szymanski, 1999) and to disengage from (Hellermann \& Cole, 2009; Szymanski, 1999) teacher-assigned tasks in the classroom: students display their engagement, among other means, by forming groups appropriate for the task, by establishing mutual orientation to relevant parts of the task and by producing task-related initiating actions that are implicative of responsive next actions; and students display their disengagement, among other means, by expressing their appreciation of group members accomplishing the task, by taking up individual activities and by refraining from further talk once the task has been completed. Moreover, drawing on longitudinal data from language classrooms, Hellermann (2007) and Hellermann and Cole (2009) present evidence of learning, which is understood as changes in participation in the various social practices of engagement and disengagement over time (see also Martin \& Sahlström, 2010). Similarly, Fatigante, Liberatia and Pontecorvo (2010) provide a detailed account of how children engage adults in playing games and how, afterwards, adults disengage from these joint leisure activities to perform various household chores. Additionally, Fatigante et al. (2010) highlight the prospective and retrospective orientation present in the transitions: during the transitions into game episodes, 
participants ensure the availability of co-players and, drawing on shared past experiences, shape their expectations about the activity about to begin; while during the transitions out of game episodes, participants maintain the relevance of the just finished activity, such as through their comments on each others' performances while they simultaneously project a next activity, such as through withdrawing from the area in which the game has taken place. Drawing on Goffman (1974), Fatigante et al. (2010) go on to argue that the backward- and forward-looking orientation of transitions results in their both belonging and not belonging to the activities that they bracket.

Our analysis focuses on an activity that families with children may engage in together: foraging for wild produce. The majority of our research materials have been gathered in Finland, where foraging is a widely practiced and culturally valued everyday activity. For a substantial number of people in Finland, foraging forms a significant part of life every autumn when various wild produce, including berries (such as blueberries, cloudberries and lingonberries) and mushrooms (such as boletuses, chanterelles and milk caps), are in season. When they return home, they clean the wild produce, possibly process it somehow and then freeze or preserve the produce so that it can be eaten later during the winter months. The research materials are part of a project in which we attempt to describe how different types of activities in nature are accomplished socially in situ, and here we focus on the social organization of foraging. We have approached the research materials by identifying moments within single interactional episodes when participants evidently carry out a slight reorientation in their foraging, one that may require them to move from one location to another or to switch between manual and pedal practices, so to speak, but not to enter into a significantly different type of space or to put into operation a fundamentally different set of material resources (cf. Fatigante et al., 2010; Goodwin \& Cekaite, 2013). Thus, rather than provide an etic definition of 'transition' and 'activity', or focus solely on the design of actions such as instructions or proposals (see Stivers \& Sidnell, 2016) in foraging, we demonstrate that by employing a range of vocal and bodily means, participants manage transitions 
between 'searching' and 'picking', achieving relevant continuity throughout the entire activity (see Keevallik, 2010). While the means employed by the foragers may be similar to those used in other contexts, the particular characteristics of foraging also arise in transitions within the activity: foraging is based on sufficient iteration and its successful completion is negotiable to a larger extent than, for example, a classroom task or a round of a computer game. Furthermore, we show that by accomplishing transitions, the participants in our data orient to defining what foraging is about, both as an activity and for their family.

\section{Research materials and methods}

We draw on approximately 12 hours of video data in English and Finnish that capture families with children as they are engaged in the activity of foraging in nature. These families have made the video recordings themselves, either for us or originally for their own use, and they have given their informed consent for the use of the data for research purposes. The participants' real names have been changed to pseudonyms, or family role titles, such as Mom and child. The data are particularly suited for analyzing the social organization of foraging, as the more experienced participants (typically parents or older siblings) often make visible to the less experienced participants (typically children or younger siblings) how to carry out foraging as an activity, among other means, through giving instructions. The ages of the children in the data vary from 16 months to 10 years, and their linguistic, motor and other skills vary accordingly. Even though we have longitudinal data for some of the children, the present focus is on the various ways that participants accomplish transitions in foraging, in general, and in particular, how they socialize one another into appropriate ways of doing so.

The different types of processes and practices involved (such as the use of tools and the negotiation of values attached to foraging) are made visible and accessible for participants and, through the recordings, are likewise evident to the analysts. This is the starting point for ethnomethodological 
conversation analysis (e.g. Garfinkel, 1967; Heritage, 1984; Sacks, 1992), which provides the means to examine social practices as they emerge and evolve through participation and collaboration in multiparty interactions (see, e.g. Goodwin, 1994; Goodwin, 2006).

The data have been transcribed according to the conventions described in Jefferson (2004) and Mondada (2014). Talk is written in black font while all other information appears in gray font. Possible translations into English are provided in italics. The symbol \# is used to indicate the timing of screenshots, while embodied actions and gaze have been assigned different symbols for children and adults, respectively: $\pm=$ child's embodiment; $+=$ child's gaze; $*=$ adult's embodiment; and $a=$ adult's gaze. These four symbols are used to mark the timing of different relevant actions (for example, talk, participants' gaze and bodily conduct) in relation to each other.

\section{Transitions as sites of socialization}

In this section, we analyze transitions that occur in two types of foraging activity: picking wild berries and mushrooms. These activities both involve 1) searching, during which family members move around looking for appropriate wild produce, and 2) picking, during which they collect and stow the produce that they have found. It is important to note that in the data presented here, the participants have already established the type of berries or mushrooms they are to pick and this means that they do not spend time, for example, identifying the wild produce. In this section, we illustrate how the participants employ various multimodal means in order to accomplish transitions between searching and picking. Indeed, the participants work to achieve continuity, that is, to manage the entire foraging activity, rather than the searching and picking as somehow constituting separate activities. This is often done by the adults, who offer the children opportunities for active participation and yet, on occasion, exert control in determining appropriate moments of transition. During these moments, we can also 
observe how participants orient to transitions at appropriate points as enabling effective and economical foraging.

\subsection{Transitions in foraging}

Let us first examine a typical transition that occurs in a family foraging activity. In Example 1, an English-speaking family of three is picking mushrooms, and the family members draw on various laminated vocal and bodily resources to bring to an end their picking the mushrooms within an arm's reach and to initiate searching for new ones. The father video-records the foraging activity and participates in it from behind the camera, while the mother and the one-and-a-half-year-old child are in view most of the time. For this reason, when analyzing the data, we have also considered the movement of the camera as providing us some access to what the father is doing. Before the beginning of this example, the family has stayed in the same spot for a minute or so, and the mother and the child have cut three mushrooms from the ground. They have already put the first and second mushroom into their bag, and now the mother is holding the third one in her left hand.

(1) 02 HANS Picking mushrooms (T: 00:00:48)

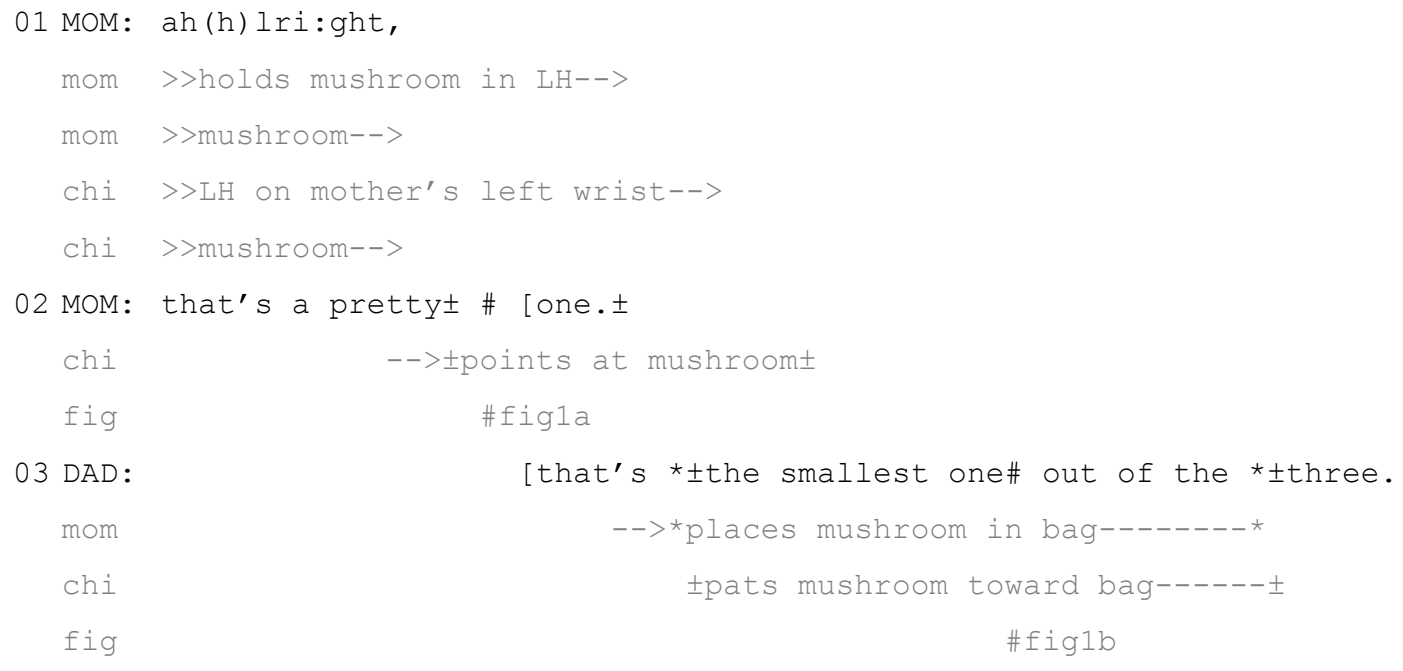




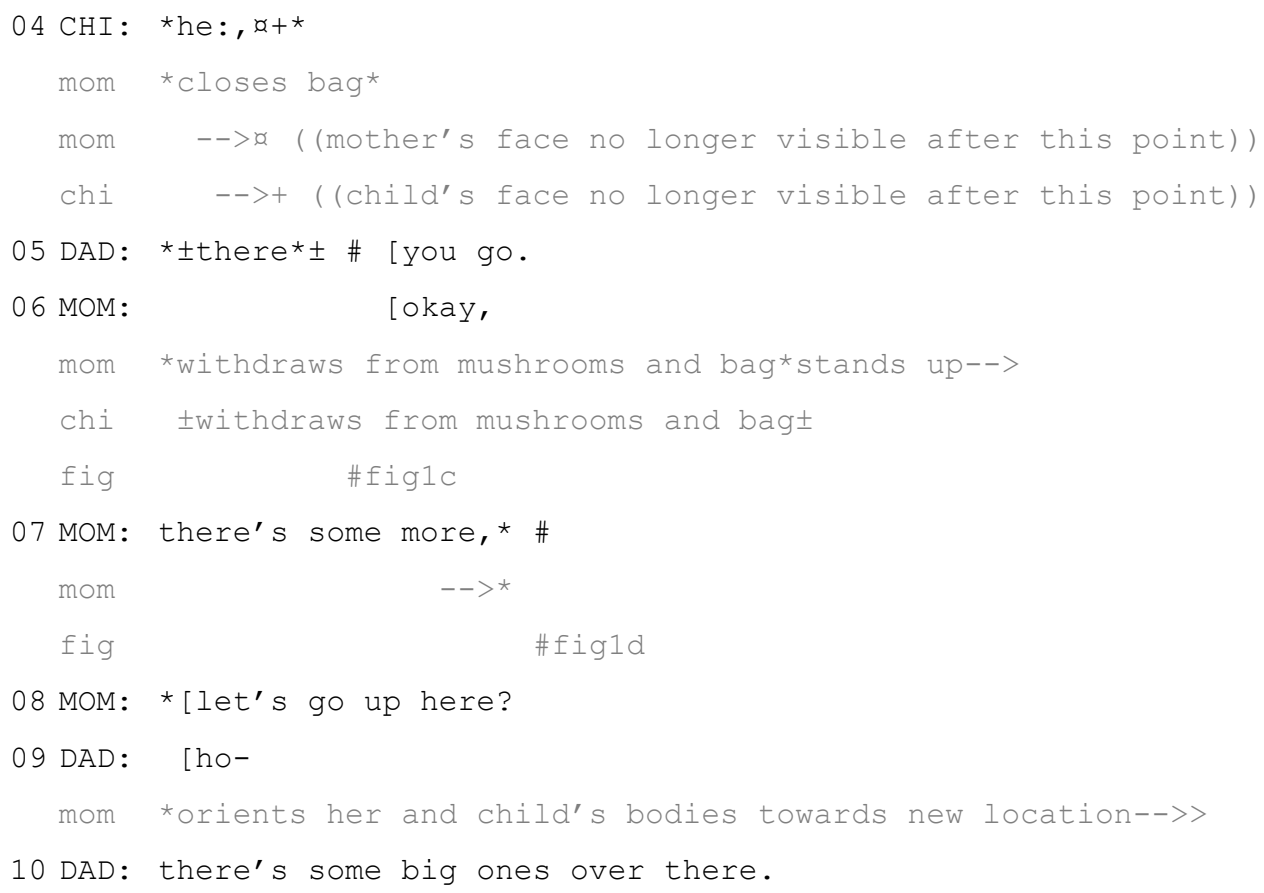

In Example 1, picking the nearby mushrooms is brought to a close through assessments and the physical handling of the bag. The mother's that's a pretty one (line 2) as well as the father's that's the smallest out of the three (line 3) evaluate their latest pick, which the mother continues to hold in her hand. The child also displays that she shares the mutual focus of attention by pointing at the mushroom in her mother's hand (Figure 1a). Of these actions, the father's turn in particular is oriented to the current stage of their foraging activity: the smallest out of the three refers to the amount of mushrooms that were available at this particular spot, and so implies the end of picking here. In this context, the child's vocalization, he:: (line 4), can also be heard as a contribution to the assessment sequence. At the same time with the last two assessments by the father and the child (lines 3 and 4), the mother places the mushroom in the bag that is lying open on the ground and closes the bag. The child also contributes to this next relevant thing to do by patting and pushing the mushroom toward the bag (Figure $1 \mathrm{~b}$ ). The child actually stows the mushroom in concert with her mother even though the parents have not verbally instructed the child to do so. Finally, as part of the verbally produced closing, the father says 
there you go (line 5) and in this way evaluates the participants' - and perhaps mostly, the child's accomplishment, their having completed picking at this spot.

At this point, the mother and the child already seem to be orienting away from the mushrooms that they have just picked (line 5, Figure 1c). The mother then also verbally initiates a move from picking and stowing mushrooms to searching for new mushrooms, with okay, there's some more (lines 6, 7). Okay in itself has been shown to occur at transition points, where it projects a continuation, a next action by the speaker (e.g. Beach, 1993, 1995). There's some more is indeed a continuation because it refers to another spot where mushrooms can be found and, in a sense, serves as a proposal to reiterate the picking there. Through their bodily actions, the participants also display their understanding that the searching requires movement. The participants begin to move towards the new location by turning their (or the camera's) gaze away from the current spot and up the hill, by orienting their bodies in that direction and by getting up to walk (lines 6-8, Figure 1d) (e.g. Modaff, 2003). It is therefore clear that this transition also involves a physical transition from staying put, squatting and picking, to getting up to move and find more mushrooms. For the child, this also means that she is physically guided, or 'shepherded' (Cekaite, 2010), through the transition, and that her participation in the activity is thus regulated by the parents.

\subsection{Securing the continuity of activities over transitions}

As Example 1 showed, transitions in foraging are managed through a range of linguistic and bodily means, and some of these can be more readily be understood as closing and others as initiating. However, what is most striking about this example, and at the same time, most unremarkable, is the fluidity of the participants' coordinated and jointly accomplished actions, which take them from picking mushrooms to searching for more without any evident hitches or delays (see Fatigante et al., 2010). The participants in Examples 2 and 3 similarly manage transitions in a continuous fashion, but 
here the means are, at least initially, more subtle than in Example 1. In Examples 2 and 3, the adult orients to keeping the child engaged in the foraging, be it picking or searching, and thus to securing the continuity of their ongoing activity. The child, in turn, takes up the prompts and proposals by the adult, accepting the way how the adult defines and delimits the activity for them both.

In Example 2, a two-and-a-half-year-old child sits on the ground, picking and eating lingonberries, while his mother records the situation. The mother secures the continuity of their ongoing activity and a transition from picking to searching, first, by guiding her child to establish that there are no more berries to pick within an arm's reach and, then, by proposing that they move to a new location. Before the beginning of the example, the child has picked a berry and put it into his mouth. Here, he is chewing the berry while also bending forward and keeping his right hand up in a type of picking position (Figure $2 \mathrm{a}$ ).

(2) 03 HANS Puolukassa / Picking lingonberries (T: 00:00:12)

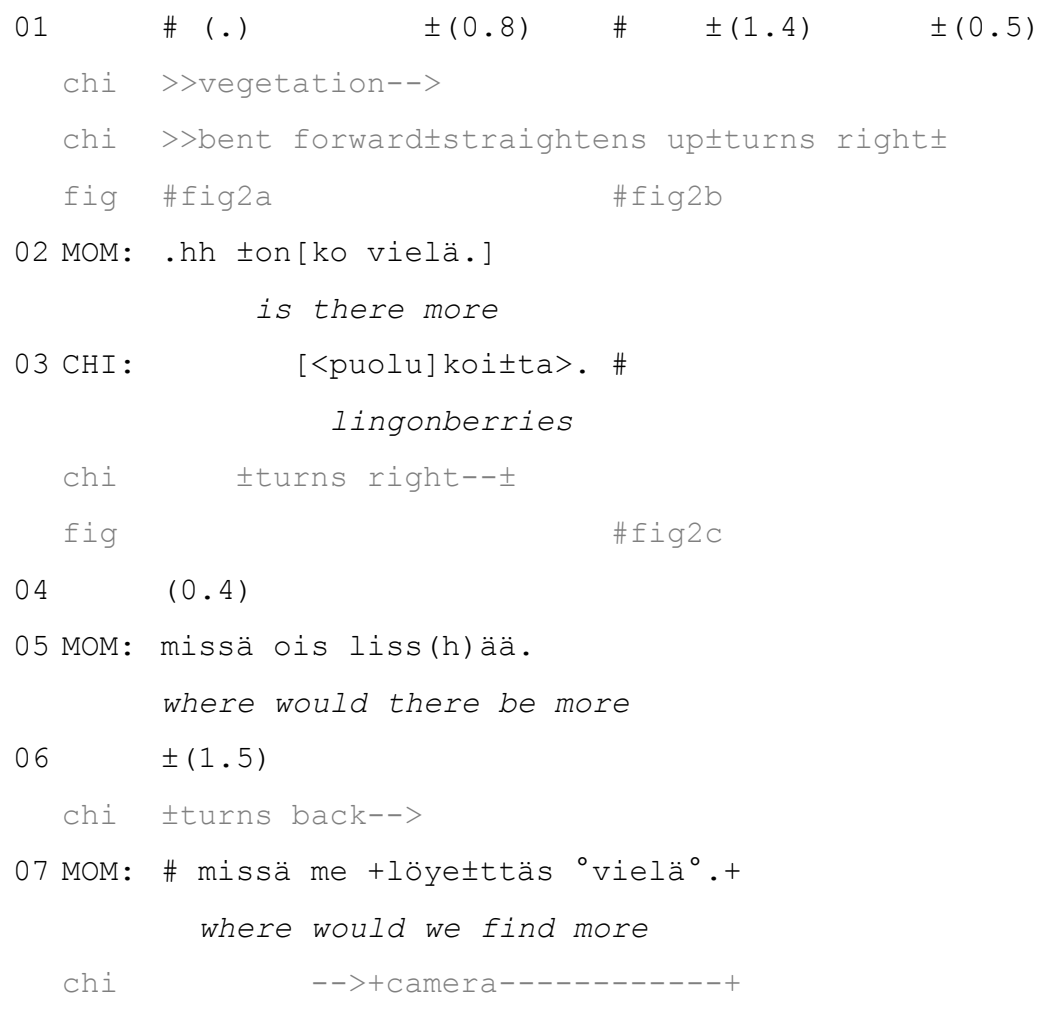




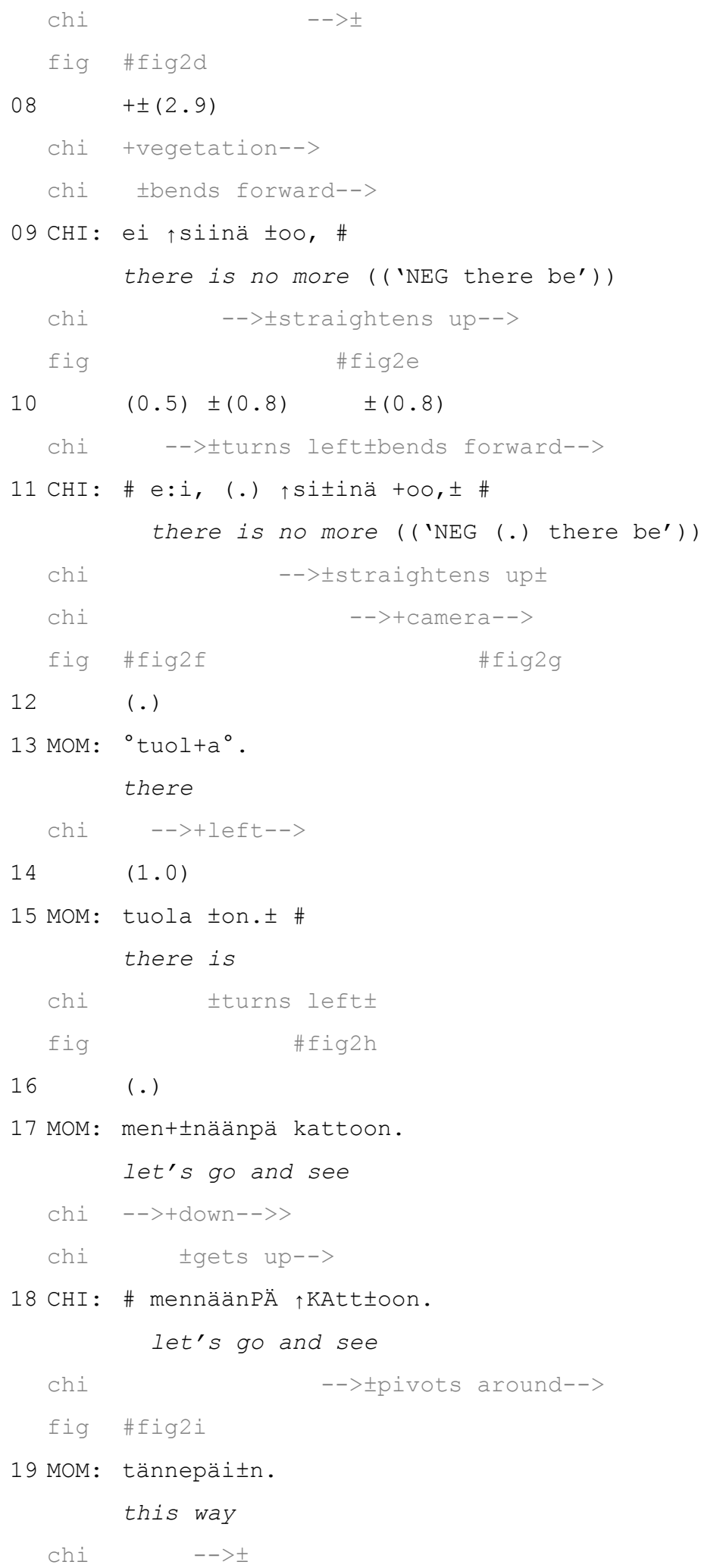


In lines $1-3$, the participants can be seen to orient to their immediate surroundings as a possible location for finding more berries: after straightening up, the child turns his upper body to the right and keeps his gaze on the vegetation (Figures $2 b-c)$, and his mother encourages such scanning by asking the child onko vielä 'is there more' (line 2). When the child has turned his upper body more or less to the maximum but remains still, evidently without spotting any berries, his mother prompts him to continue scanning, missä ois lissä̈̈ 'where would there be more' (line 5). In contrast to the initial yes/no interrogative, the $w h$ interrogative suggests that the scanning be extended to a wider area, so that the question is indeed where, rather than whether, there are more berries nearby. The child then slowly returns from the 'body torque' (Schegloff, 1998), during which the orientation of his lower body has remained towards the mother, and he again maintains his gaze on the vegetation and his right hand in a picking position (Figure 2d). The mother's subsequent prompt highlights the joint nature of the activity by presenting both of them, we, as agents in it: missä me löyettäs vielä 'where would we find more' (line 7). The child responds to that prompt not only by scanning the surroundings more closely (by bending down towards the vegetation, Figures $2 \mathrm{e}-\mathrm{f}$ ), but also by reporting the findings of the scanning (ei siinä oo 'there is no more', lines 9 and 11).

The child finishes the scanning by verbally noting that there are no more berries to pick (line 11), straightening up his body and turning his gaze to the direction of his mother (i.e. the camera, Figure $2 \mathrm{~g}$ ). In this way, the child indicates that he has in fact exhausted the berries around him and is now available for further guidance from his mother. His mother then whispers a 'direction indication' (Gazin, 2015), tuola 'there' (line 13), to which the child responds by turning his gaze to the left; and when his mother utters another direction indication (tuola on 'there is', line 15), the child turns his whole upper body slightly to the left (Figure $2 \mathrm{~h}$ ). It is therefore only after his mother has pointed out another possible spot to find berries that he begins to orient further away from where he is sitting. Nevertheless, as the child orients to the relevance of a transition from picking to searching, he also 
picks up on the relevance of a physical transition: his mother has only produced the first syllable of an utterance that proposes a move to another location (mennäänpä kattoon 'let's go and see', line 17) when the child begins to get up on his feet (Figure 2i). Additionally, the child repeats his mother's proposal word-for-word (line 18), indicating the projected course of action to have evolved somewhat independently of the proposal and claiming, in a sense, equal rights to participate in the activity that is proposed (see VISK $§ 1216)$.

Throughout the transition, the mother first employs relatively subtle and then more direct means to guide her child, thus offering her child opportunities for active participation in the ongoing activity. First, the mother's interrogatively formatted prompts for the child to scan their surroundings become increasingly implicative of a transition, gradually widening the area to be covered and extending the activity to involve both the child and his mother. Second, the mother first whispers and then produces with regular phonation direction indications and these imply that a move to another location would be relevant. Third, the mother's explicit proposal to move is produced when the participants have established both the end of picking in the current spot and the start of searching in a new spot (albeit with a clear idea of where that new spot might be). The camera's movement (not indicated in the transcript) reveals that the mother likewise gets up, or possibly straightens up from her squatting position, at the same time as the child and begins to walk towards the next picking spot, and she further guides the child in the appropriate direction (line 19 and onward, data not shown).

By prompting and proposing that they search for more berries, either within or beyond an arm's reach, the mother in Example 2 keeps the child occupied and engaged in the foraging activity. The child also orients to such guidance, most of the time, by simply scanning his immediate surroundings and, after establishing that there are no more berries to pick there, by shifting his gaze towards his mother in pursuit of another prompt or proposal. The continuity of the activity is thus accomplished in collaboration between the participants. 
Example 3 presents another case from the same family, only this time, the child is a year older, that is, three and a half years old, and he is picking blueberries with this grandfather. As the child is older, he shows more autonomy both in how he moves in the woods and in how he forages for berries. The adult's prompts, in turn, are even more subtle than in Example 2 and build substantially on the projected trajectories of the child's actions. As in the previous example, the mother records the situation. The grandfather, who has already begun to pick berries at a particular spot, guides the child to do the same.

(3) 06 HANS Mustikassa I / Picking blueberries (T: 00:04:25)

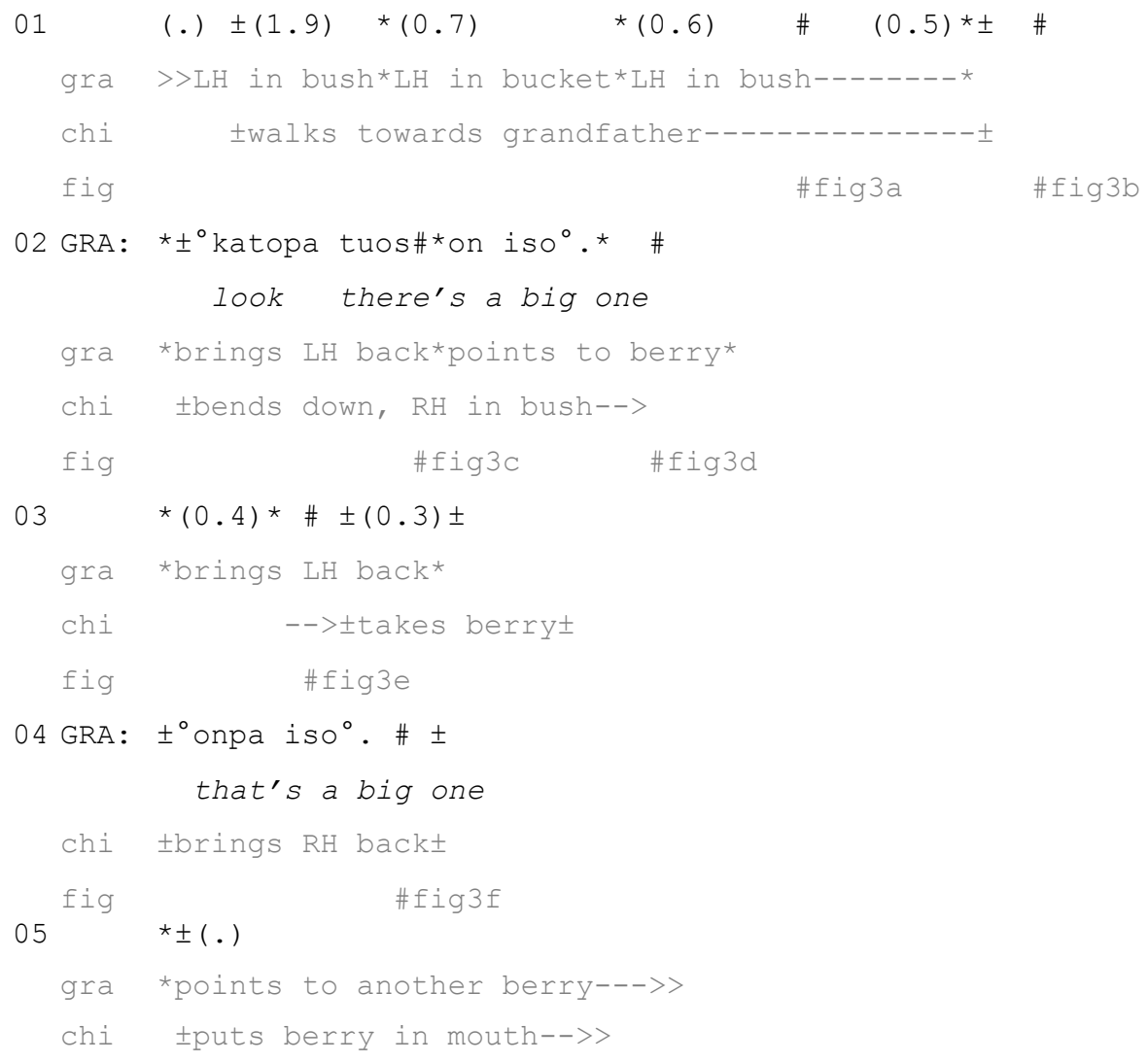

As the example begins, the grandfather is holding a bucket in his right hand and using his left hand to pick berries and drop them into the bucket (Figure 3a). The child has stayed slightly behind, 
standing by his mother and partly off camera. At the beginning of Example 3, the child walks towards his grandfather (line 1; Figure 3a) and then stops in front of the bush where the grandfather is picking berries. By positioning himself in this manner, the child displays his availability and readiness to engage in some form of activity and interaction with his grandfather. Moreover, the child seems to be managing a transition from searching to picking berries by drawing on his grandfather's current position and engagement in picking as an indication of a relevant new location: once the child has reached the berry bush, he bends down slightly and stretches out his right hand towards the bush (Figures $3 b-c)$. At the same time, his grandfather stops reaching for berries and instead brings his left hand back to point at a berry with his index finger (Figures $3 b-c$ ), and he also directs the child's attention to that berry by whispering katopa tuoson iso 'look there's a big one' (line 3). This 'environmentally coupled gesture' (Goodwin, 2007), which presents the size, location and availability of particular wild produce as relevant and appreciatable, functions both in prompting the child to move on to pick berries and in ratifying the child's current conduct as appropriate. After the child has picked a berry from within the area that his grandfather pointed towards, his grandfather assesses the size of the find, still in a whisper (onpa iso 'that's a big one', line 6; Figures $3 \mathrm{~d}-\mathrm{f}$ ), and the child puts the berry into his own mouth. The grandfather then continues to point out berries to the child, and the child continues to pick and eat berries directly from the bush (line 5 and onward, data not shown).

In Example 3, the grandfather employs very subtle means to support the child in managing a transition from searching to picking: the grandfather changes the trajectory of his hand from reaching for berries to pointing some out to his grandchild and the grandfather also produces positive evaluations of the finds in a whisper. This secures the continuity of their ongoing foraging activity, maintaining their focus on the activity itself and minimizing the role of the grandfather while maximizing that of the child. Furthermore, the grandfather uses these means to constrain the circle of possible participants and constructs the activity as something private, shared only by him and his 
grandchild. In a sense, then, the grandfather's conduct can be seen to "encourage childhood qualities of initiative, self-reliance, and individual agency while simultaneously rewarding and promoting close interdependent familial ties" (Sirota, 2006, p. 509). That is, the grandfather highlights both the child's autonomy and their joint engagement in the activity.

\subsection{Accomplishing the social order of foraging}

The previous sections have demonstrated how transitions are achieved in the finely tuned collaboration between participants and how participants' actions contribute to securing the continuity of the foraging activity. Because the more experienced participants particularly orient to transitions as relevant and their timely and coordinated achievement as important for the progression of the foraging activity, these normative orientations also provide the basis for why transitions are significant in socializing less experienced participants into the practices and social norms of foraging.

Example 4 involves a family of three who are engaged in mushroom picking. These are the same participants as in Example 1. In the process of picking and stowing away the mushrooms that they have picked, the child initiates a transition from picking mushrooms to moving to a new location. However, she is guided not to go forward before all the mushrooms in the current spot have been picked.

(4) 02 HANS Picking mushrooms (T: 00:01:25)

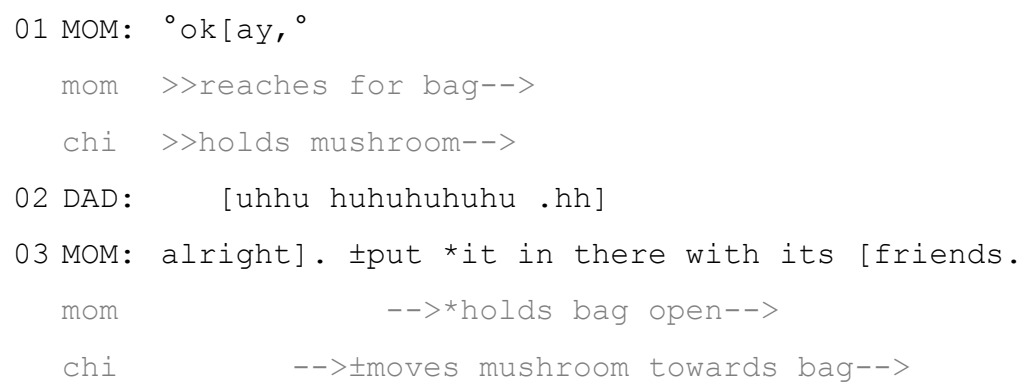




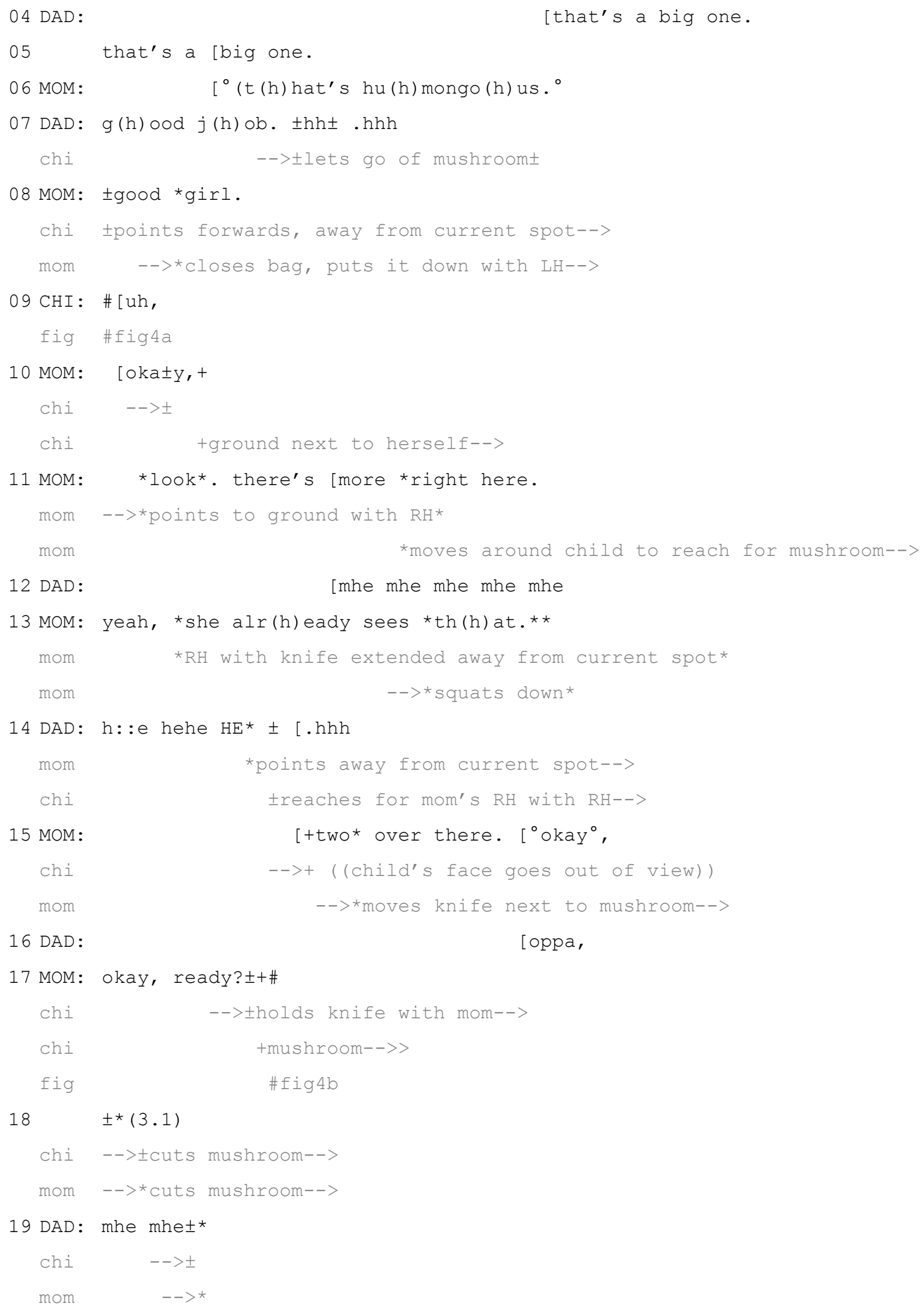


Just prior to this excerpt, the mother and her child have picked a mushroom together. The child is holding the mushroom when her mother initiates a transition in the activity with okay (line 1) (see Beach, 1993, 1995). At the same time, the mother reaches for the bag that contains the mushrooms that they have picked thus far. This is accompanied by an instruction, put it in there with its friends (line 3), which makes explicit what is to be done with the mushrooms once they have been picked. The instruction is produced as a directive, which has been shown to serve as one major means to guide less experienced participants to adopt the recurrent practices of their social environment (Cekaite, 2010; Goodwin, 2006). Here the child follows the instruction by placing the mushroom in the bag. Both parents then evaluate the child's actions with positive assessments (lines 7-8). These turns close the sequence and one iteration in the mushroom picking activity.

At this intersection in their foraging, both the mother and her child initiate a new action. The mother, on the one hand, again uses okay (line 10) to indicate a transition. However, unlike what occurs in Example 1, the transition does not involve a move to a new location but a new round of picking in the current spot. This is made evident by the mother's embodied actions: once the child has placed the mushroom in the bag, the mother continues to orient her body, and especially her right hand that holds the knife, towards where they picked the previous mushroom (Figure 4a). The child's initiating action, on the other hand, consists of a point (Figure 4a) and a vocalization $u h$ (line 9). As we can see, the mother interprets this as initiating a move towards a new location: she proceeds to guide her child to remain in their current location with look. there's more right here (line 11) and by pointing to a mushroom near their feet. The child follows her mother's guidance by shifting her gaze to the mushroom close to them, bending down, and by reaching for her mother's right hand in order for them to cut the mushroom together (Figure 4b). The mother also verbalizes her understanding of her child's actions as an initiation to move to a new location with she already sees that (line 13) and by identifying two mushrooms at some distance (line 15). While these turns are primarily produced as a commentary 
for the father, they also offer us access to the participants' online analysis of the ongoing activity. Importantly, these few turns indicate how the one-and-a-half-year-old child, with limited linguistic skills, is treated as a legitimate participant whose actions are also relevant for the foraging activity.

In Example 4, changes in participation are displayed as the less experienced participant discovers and tries out the proper temporal, embodied and sequential order of activities. With young children, such as in Example 4, parents frequently guide the activity. In the case of picking mushrooms or berries, initiations by the less experienced participants - or the lack of relevant initiations - may be interpreted as non-normative actions (as indicated by actions which in essence involve "let's not move yet" or "let's move"). Instead, the less experienced participants are instructed to participate in the activity in appropriate ways. In Example 4, this involves picking everything from the current spot before moving forward.

Example 5 presents another case in which an initiation by a less experienced participant is treated as untimely in the progression of the foraging activity. In this example, a family of five is picking blueberries. Just prior to this excerpt, one of the three children has tripped, become entangled in the vegetation and has struggled to get up. The father has helped her, after which he has resumed picking berries. The following exchange takes place immediately after and involves the father and the daughter who is still upset.

(5) HANS 24 Mustikassa IV / Picking blueberries (T: 00:12:00)

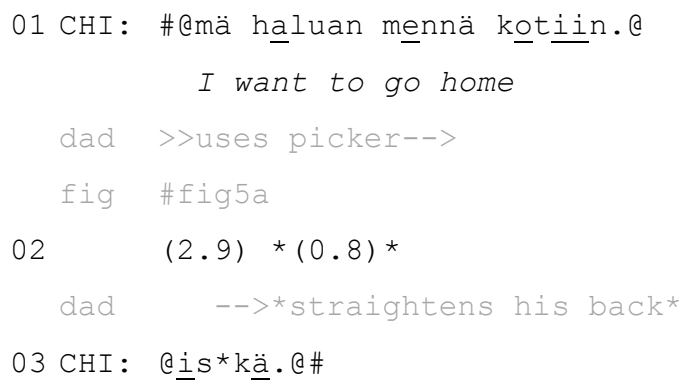




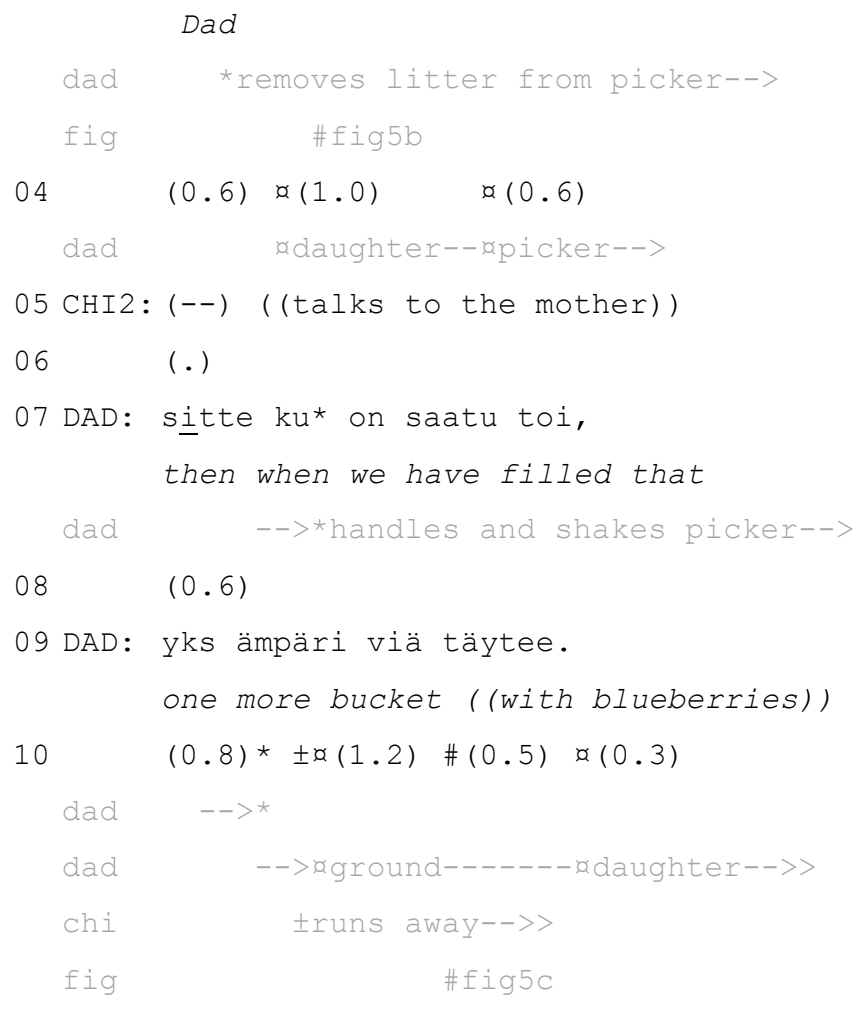

The child has already disengaged from active berry picking some time ago and has explored the woods, staying relatively close to her parents. In this case, the child is older (6 years) and more autonomous than the children in previous examples, and the parents give her more leeway in how she participates in berry picking. Here, for example, the child has not been explicitly guided to resume berry picking after her fall, but instead, the parents lead by example. Soon after the father himself has resumed berry picking, the child expresses her wish to go home (line 1). The child's initiation to end the foraging is treated as untimely in many subtle ways. First, the response to the child is delayed, as a 3.7-second pause in talk ensues (line 2). During this, both parents continue to pick berries and maintain the same body position as they had before the child's turn (Figure 5a). The father takes a couple of scoops of berries, and sibsequently straightens his back. However, he continues to orient to the berry picker and does not look at the child but at the picker in his hand. As no immediate response is forthcoming, the child pursues a response by directly addressing her father with iskä 'Dad' (line 3). 
However, her father continues to handle the picker and removes some twigs from it (Figure 5b) and he only briefly directs his gaze towards his child (line 4). The father is therefore ostensively occupied with the berry-picking activity. The father's response to his child's initiation follows after some intervening, but non-related talk by another child (line 5); the father says sitte ku on saatu toi, yks ämpäri viä täytee 'then when we have filled that, one more bucket' (lines 7 and 9). In so doing, the father implicitly rejects the child's proposal to go home. Or rather, he provides an account of the expected conduct and the temporal length of berry picking: one should pick enough berries (here 'one more bucket') before leaving the woods and going home. This displays the father's orientation to the appropriate social order of foraging. The child does not challenge her father's account but closes the topic by running away (Figure 5c). In short, by continuing the ongoing activity, by delaying his response and by explicating their berry-picking goals, the father treats his child's proposal to go home as untimely.

\section{Discussion}

This study has explored the means that participants draw upon to manage transitions in foraging, and more specifically between 'searching' and 'picking', or vice versa. For example, the participants in our data provide assessments and evaluations of finds that they have sighted or already picked to implicate the relevance of a transition, produce explicit prompts and proposals with possible direction indications to initiate a transition as well as use conventionalized linguistic items to mark off moments of transition. Moreover, these verbal means are interwoven with the participants' handling both the catch and possible picking equipment, shifting their gaze in relevant directions as well as orienting and moving their bodies in coordination with one another and the surroundings.

More specifically, our interest has focused on how, while alternating between searching and picking, participants manage to maintain their joint engagement in the foraging. We have shown that particularly the adults, the more experienced foragers in our data, orient to the overall progression of 
the foraging and work to keep the children engaged in it. They do this either by guiding children to iterate what they have just done (as in Example 4), by prompting them to move on (as in Example 1), or by providing accounts of the aims of the activity (as in Example 5). It is worth noting that in these data and in such a natural setting, the children are most of the time actively involved in foraging and thus gain important hands-on experience of relevant practices, processes and procedures (see Lindwall \& Ekström, 2012). In principle, the adults offer the children opportunities for active participation, quickly taking up the children's initiatives and playing down their own role in accomplishing transitions (as in Example 3). Nevertheless, the adults can also deem the children's initiatives untimely and resist them, and they do this by simply ignoring them, proposing alternatives and providing accounts (as in Examples 4 and 5). In this way, the children may become accustomed to how competent foragers, in this family or in this community at large, determine and negotiate appropriate moments of transition. That is, by prompting children to move on when berries from a particular spot have been exhausted, to stay put when there are still mushrooms to pick in the same spot or, indeed, to continue foraging until the participants are satiated or their containers full, the adults convey the social order of foraging and the values that determine how foraging may be carried out most economically and efficiently.

From a cultural perspective, foraging has developed over the years from a necessary act of survival to an activity that continues to provide additional sustenance for a substantial number of people in Finland, among others. At the same time, foraging provides opportunities to spend time outdoors, in the company of relevant others, and for some, this may be their most important motivation for engaging in this activity. These cultural presuppositions and practices are visible in the materials examined in this study, in the various ways that foraging for berries or mushrooms is constructed as a completely mundane, everyday activity. Furthermore, it is possible to detect during the moments of transition how the adults strike a balance between constructing foraging as a serious, sustenance- 
providing activity, on the one hand, and as an enjoyable family pastime, on the other. In any case, transitions in foraging are collaboratively accomplished achievements, used to secure the continuity and progression of this iterative activity as well as for negotiating appropriate involvement in the activity. On a more general level, and outside of foraging activities, the moments of transitions provide the opportunity for the possible redefinition of participation and action.

\section{Acknowledgments}

We have presented versions of this study at the Revisiting Participation conference in Basel in July 2015, the Finnish Seminar on Conversation Studies in Turku in March 2016, and the VII Conference on Childhood Studies in Turku in June 2016 as well as at Högre seminariet at IKK in Linköping in March 2017. We thank the participants at these events for their generous and supportive comments on our work. We also wish to thank Leena Kuure, Anna Suorsa and other members of the COACT research community at Oulu for reading and commenting on very early drafts, and the editors and reviewers of LCSI for helping us improve the manuscript.

Funding: This study was supported by the Academy of Finland [decision number 285393], the University of Oulu and the Finnish Centre of Excellence in Research on Intersubjectivity in Interaction, University of Helsinki [Academy of Finland, decision number 284595].

\section{References}

Beach, W. (1993). Transitional regularities for 'casual' "Okay” usages. Journal of Pragmatics, 19, $325-352$.

Beach, W. (1995). Conversation analysis: "Okay" as a clue for understanding consequentiality. In S. J. Sigman (Ed.), The consequentiality of communication (pp. 121-162). Hillsdale, NJ: Lawrence Erlbaum. 
Broth, M., \& Keevallik, L. (2014). Getting ready to move as a couple: Accomplishing mobile formations in a dance class. Space and Culture, 17(2), 107-121.

Broth, M., \& Mondada, L. (2013). Walking away: The embodied achievement of activity closings in mobile interaction. Journal of Pragmatics, 47, 41-58.

Cekaite, A. (2010). Shepherding the child: Embodied directive sequences in parent-child interactions. Text \& Talk, 30(1), 1-25.

Fasulo, A., Lloyd, H., \& Padiglione, V. (2007). Children's socialization into cleaning practices: A cross-cultural perspective. Discourse \& Society, 18, 11-33.

Fatigante, M., Liberatia, V., \& Pontecorvo, C. (2010). Transitions in and out of games: How parents and children bracket game episodes at home. Research on Language and Social Interaction, 43(4), $346-371$.

Forrester, M. A. (2013). Mutual adaptation in parent-child interaction: Learning how to produce questions and answers. Interaction Studies, 14(2), 190-211.

Garfinkel, H. (1967). Studies in ethnomethodology. Englewood Cliffs: Prentice-Hall.

Gazin, A.-D. (2015). Instructional sequences in the moving car: A conversation analytic approach to multimodal interaction in driving lessons. Doctoral dissertation. University of Bern.

George, R. (2013). 'What's a vendetta?' Political socialization in the everyday interactions of Los Angeles families. Discourse \& Society, 24(1), 46-65.

Goffman, E. (1974). Frame analysis: An essay on the organization of experience. New York, NY: Harper and Row.

Goodwin, C. (1994). Professional vision. American Anthropologist, 96(3), 606-33.

Goodwin, C. (2007). Environmentally coupled gestures. In S. Duncan, J. Cassell \& E. Levy (Eds.), Gesture and the dynamic dimensions of language (pp. 195-212). Amsterdam: John Benjamins Publishing Company. 
Goodwin, C., \& Goodwin, M. H. (2004). Participation. In A. Duranti (Ed.), A companion to linguistic anthropology (pp. 222-244). Oxford: Basil Blackwell.

Goodwin, M. H. (2006). Participation, affect, and trajectory in family directive/response sequences. Text and Talk, 26(4/5), 513-542.

Goodwin, M. H., \& Cekaite, A. (2013). Calibration in directive/response sequences in family interaction. Journal of Pragmatics, 46, 122-138.

Hellermann, J. (2007). The development of practices for action in classroom dyadic interaction: Focus on task openings. Modern Language Journal, 91(1), 83-96.

Hellermann, J., \& Cole, E. (2009). Practices for social interaction in the language-learning classroom: Disengagements from dyadic task interaction. Applied Linguistics, 30(2), 186-215.

Heritage, J. (1984). Garfinkel and ethnomethodology. Cambridge: Polity Press.

Jefferson, G. (2004). Glossary of transcript symbols with an introduction. In G. Lerner (Ed.), Conversation analysis. Studies from the first generation (pp. 13-31). Amsterdam: John Benjamins Publishing Company.

Jenkins, L. (2015). Negotiating pain: The joint construction of a child's bodily sensation. Sociology of Health \& Illness, 37(2), 298-311.

Keel, S. (2011). The parents' questioning repeats in response to young children's evaluative turns. Gesprächsforschung, 12, 52-94.

Keel, S. (2016). Socialization: Parent-child interaction in everyday life. London: Routledge. Keevallik, L. (2010). Marking boundaries between activities: The particle nii in Estonian. Research on Language and Social Interaction, 43(2), 157-182.

Laurier, E. (2008). Drinking up endings: Conversational resources of the café. Language \& Communication, 28(2), 165-181. 
Lave, J., \& Wenger, E. (1991). Situated Learning. Legitimate Peripheral Participation. Cambridge: Cambridge University Press.

LeBaron, C., \& Jones, S. (2002). Closing up closings: Showing the relevance of the social and material surround to the completion of an interaction. Journal of Communication, 52(3), 542-565.

vom Lehn, D. (2013). Withdrawing from exhibits: The interactional organisation of museum visits. In P. Haddington, L. Mondada \& M. Nevile (Eds.), Interaction and mobility: Language and the body in motion (pp. 65-90). De Gruyter, Berlin.

Lindwall, O., \& Ekström, A. (2012). Instruction-in-interaction: The teaching and learning of a manual skill. Human Studies, 35(1), 27-49.

Martin, C., \& Sahlström, F. (2010). Learning as longitudinal interactional change: From other-repair to self-repair in physiotherapy treatment. Discourse Processes, 47(8), 668-697.

Mikkola, P., \& Lehtinen, E. (2014). Initiating activity shifts through use of appraisal forms as material objects during performance appraisal interviews. In M. Nevile, P. Haddington, T. Heinemann \& M. Rauniomaa (Eds.), Interacting with objects: Language, materiality, and social activity (pp. 57-78). Amsterdam: John Benjamins Publishing Company.

Modaff, D. (2003). Body movement during the transition to task in the medical interview. In P. Glenn, C. LeBaron \& J. Mandelbaum (Eds.), Studies in language and social interaction: In honor of Robert Hopper (pp. 411-422). Mahwah, NJ: Lawrence Erlbaum.

Mondada, L. (2009). Emergent focused interactions in public places: A systematic analysis of the multimodal achievement of a common interactional space. Journal of Pragmatics, 41, 1977-1997.

Mondada, L. (2014). Conventions for multimodal transcription. Retrieved from https://franz.unibas.ch/fileadmin/franz/user_upload/redaktion/Mondada_conv_multimodality.pdf

Mortensen, K., \& Hazel, S. (2014). Moving into interaction - Social practices for initiating encounters at a help desk. Journal of Pragmatics 62, 46-67. 
Ochs, E. (1996). Linguistic resources for socializing humanity. In J. Gumperz \& S. Levinson (Eds.), Rethinking linguistic relativity (pp. 407-436). Cambridge: Cambridge University Press.

Olive, M. L. (2004). Transitioning children between activities: Effective strategies for decreasing challenging behavior. Beyond Behavior, 14(1), 11-16.

Pontecorvo, C., Fasulo, A., \& Sterponi, L. (2001). Mutual apprentices: The making of parenthood and childhood in family dinner conversations. Human Development, 44(6), 340-361.

Robinson, J. D. (1998). Getting down to business: Talk, gaze and bodily orientation during openings of doctor-patient consultations. Human Communication Research, 25, 97-123.

Robinson, J., \& Stivers, T. (2011). Achieving activity transitions in physician-patient encounters. From history taking to physical examination. Human Communication Research, 27(2), 253-298.

Råman, J. (2017). The organization of transitions between observing and teaching in the budo class. Manuscript submitted for publication.

Sacks, H. (1992). Lectures on conversation. Oxford: Blackwell.

Schegloff, E. A. (1998). Body torque. Social Research, 65(3), 535-596.

Sidnell, J. (2010). Questioning repeats in the talk of four-year-old children. In H. Gardner \& M. A. Forrester (Eds.), Analysing interactions in childhood: Insights from conversation analysis (pp. 103127). Chichester: Wiley-Blackwell.

Sirota, K. G. (2006). Habits of the hearth: children's bedtime routines as relational work. Text \& Talk, $26(4 / 5), 493-514$.

Stivers, T., \& Sidnell, J. (2016). Proposals for activity collaboration. Research on Language and Social Interaction, 49(2), 148-166.

Szymanski, M. (1999). Re-engaging and dis-engaging talk in activity. Language in Society, 28(1), 123. 
Tuncer, S. (2015). Walking away: An embodied resource to close informal encounters in offices. Journal of Pragmatics, 76, 101-116.

Veen, M., \& de la Croix, A. (2016). Collaborative reflection under the microscope: Using conversation analysis to study the transition from case presentation to discussion in GP residents' experience sharing sessions. Teaching and Learning in Medicine, 28(1), 3-14.

VISK = A. Hakulinen, M. Vilkuna, R. Korhonen, V. Koivisto, T. R. Heinonen \& I. Alho (2004). Iso suomen kielioppi [Comprehensive grammar of Finnish]. Helsinki: Finnish Literature Society. Online, accessed 23 February 2017. Available at http://scripta.kotus.fi/visk URN:ISBN:978-9525446-35-7.

Winther-Lindqvist, D. (2012). Developing social identities and motives in school transitions. In M. Hedegaard, A. Edwards \& M. Fleer (Eds.), Children's development of motives: A cultural-historical approach (pp. 115-132). Cambridge: Cambridge University Press.

Wootton, A. (2007). A puzzle about 'please': Repair, increments and related matters in the speech of a young child. Research on Language and Social Interaction, 40, 171-198.

\section{Figure captions}

Figure 1a.

Figure 1b.

Figure 1c.

Figure 1d.

Figure $2 \mathrm{a}-\mathrm{c}$.

Figure 2d-f.

Figure $2 \mathrm{~g}-\mathrm{i}$.

Figure $3 a-c$. 
Figure 3d-f.

Figure 4a.

Figure $4 b$.

Figure 5a.

Figure $5 b$.

Figure 5c.
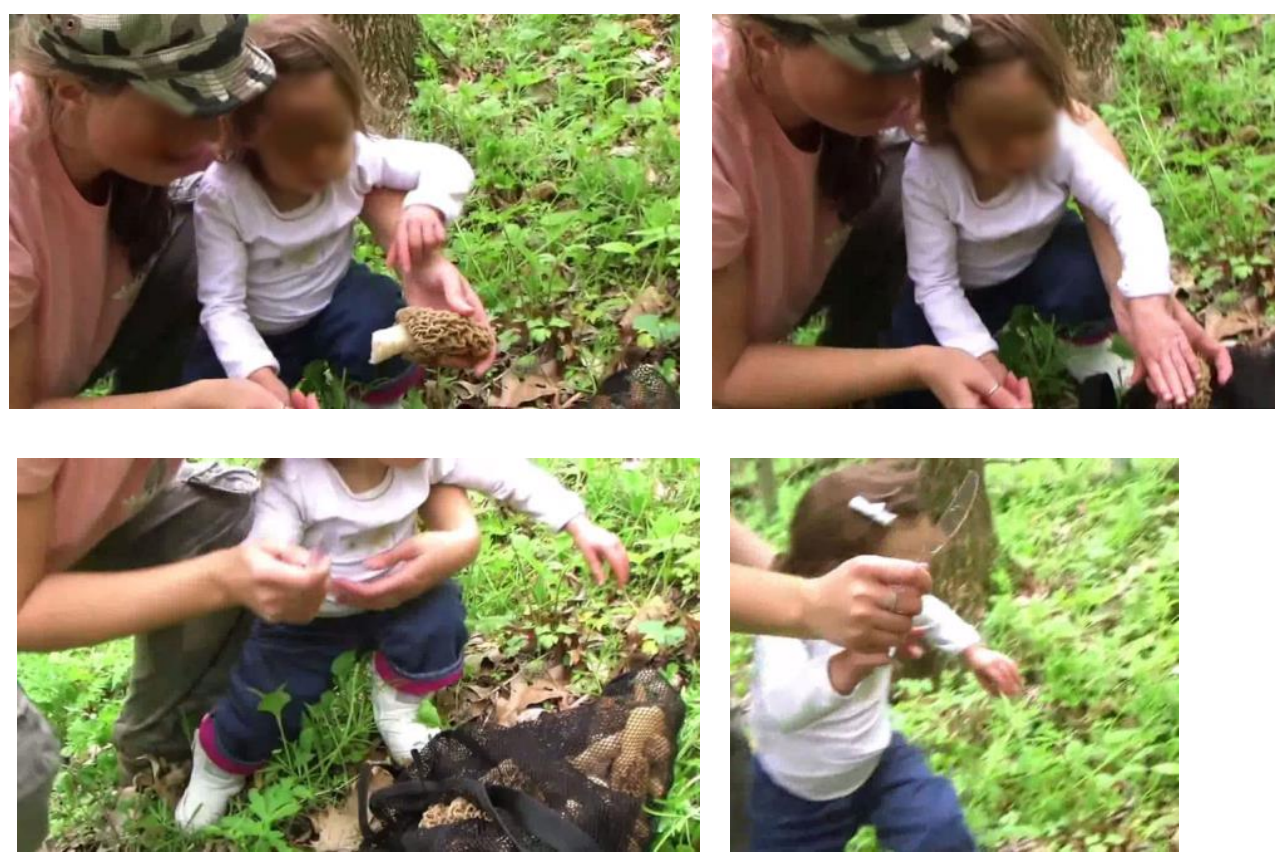

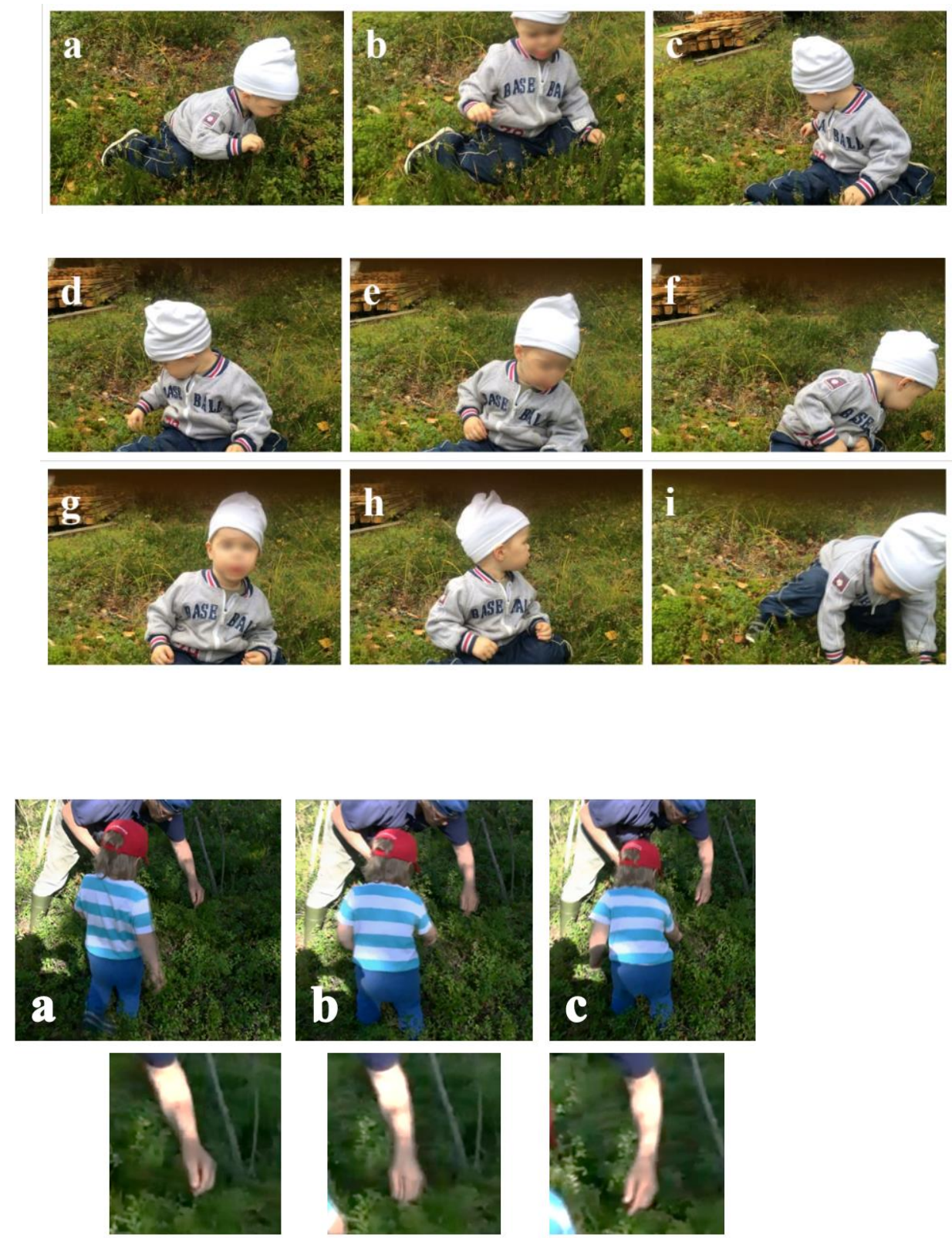

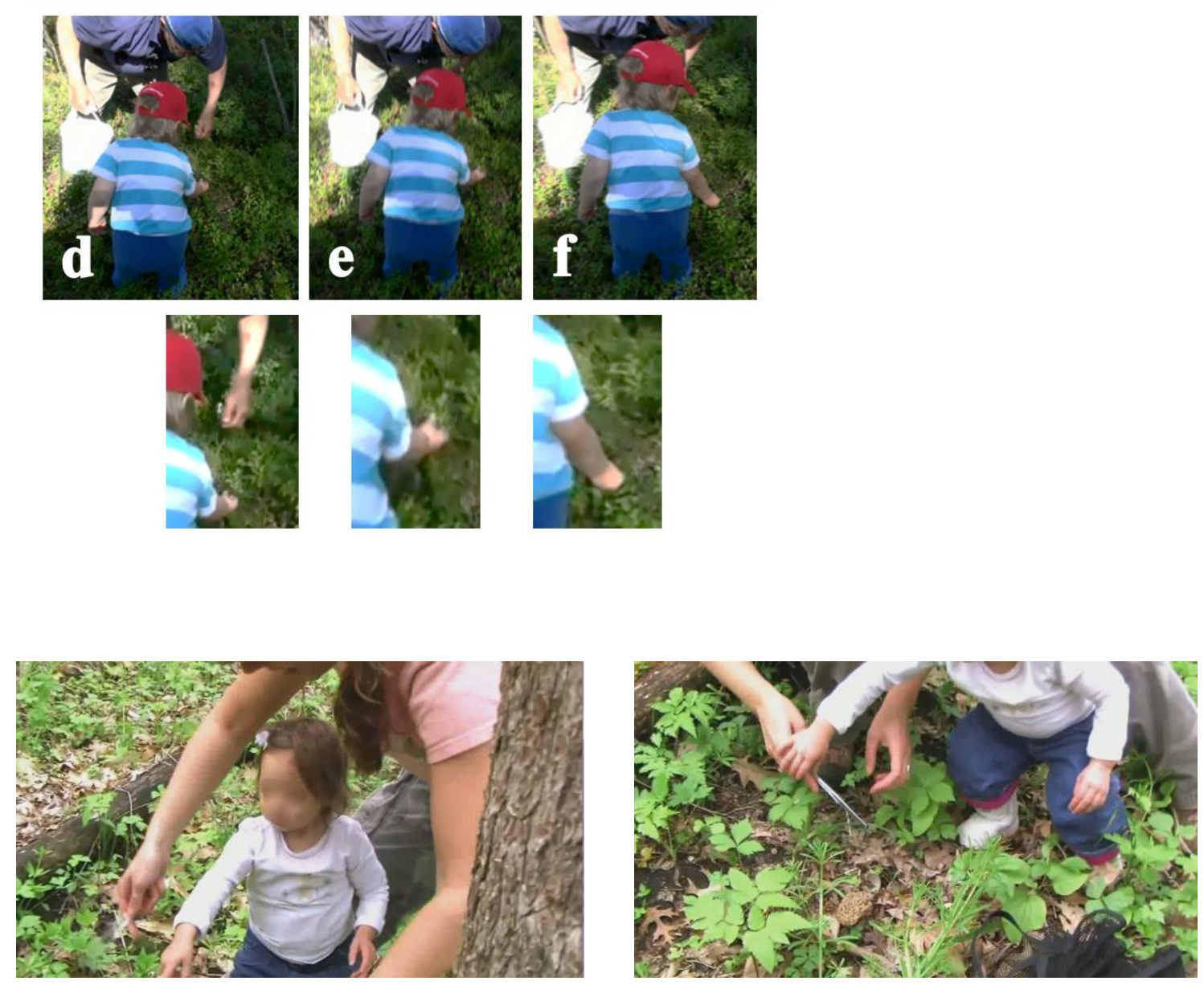

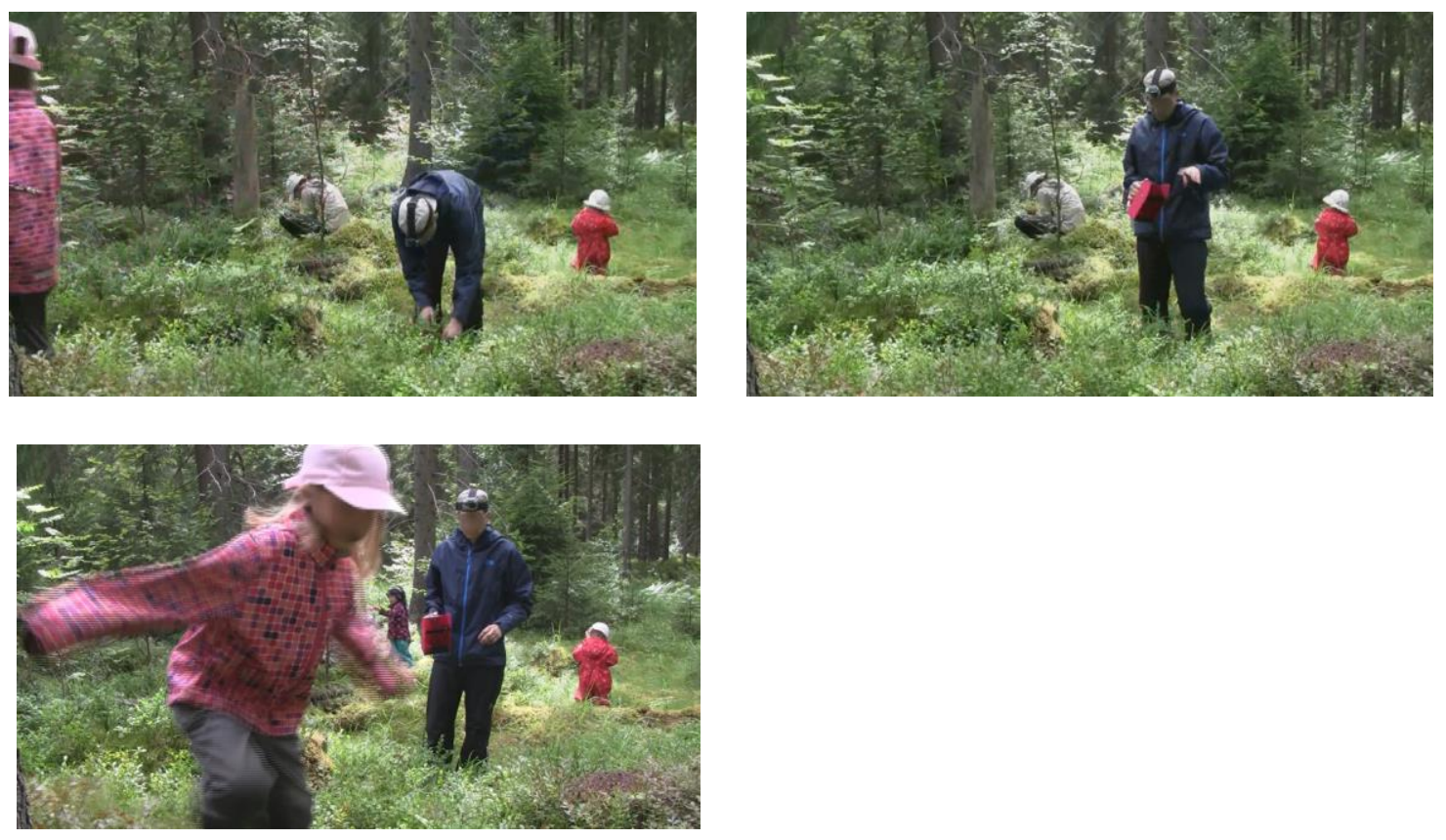